\title{
Prazosin inhibits the growth and mobility of osteosarcoma cells
}

\author{
Ming An ${ }^{1}$, Wen-Hai Ma ${ }^{1}$, Hong-Wei Jia ${ }^{1}$, Yong-Wang Li ${ }^{1}$, Jing-Jing Feng ${ }^{1}$, Jing Meng ${ }^{1}$, Hui $\mathrm{Qi}^{1}$, Jin Liu ${ }^{2}$ \\ ${ }^{1}$ Department of Orthopedics, The First Central Hospital of Baoding, Baoding 071000, China; ${ }^{2}$ Department of Gynecologic Oncology, Affiliated \\ Hospital of Hebei University, Baoding 071000, China \\ Contributions: (I) Conception and design: M An, WH Ma, HW Jia, J Liu; (II) Administrative support: M An, J Liu; (III) Provision of study materials \\ or patients: M An, WH Ma, HW Jia, J Liu; (IV) Collection and assembly of data: YW Li, JJ Feng, J Meng; (V) Data analysis and interpretation: YW \\ Li, JJ Feng, J Meng; (VI) Manuscript writing: All authors; (VII) Final approval of manuscript: All authors. \\ Correspondence to: Jin Liu. Department of Gynecologic Oncology, Affiliated Hospital of Hebei University, No. 212 Yuhuadong Road, Baoding \\ 071000, China. Email: liujinhdfy@163.com.
}

\begin{abstract}
Background: Osteosarcoma is a primary malignant bone tumor that frequently occurs in adolescents and children, its high aggressiveness and rapid metastasis often resulting in poor prognoses. In previous studies, Prazosin has been shown to possess anti-proliferative properties against prostate cancer and glioblastoma cells. In our study, we investigated Prazosin's underlying mechanisms and its effects on the biological behaviors of osteosarcoma cells.

Methods: Osteosarcoma cell lines MG63 and 143B were treated with different concentrations of Prazosin, and a CCK8 assay assessed its effect on cell viability. Colony formation, Transwell and flow cytometry assays were used to examine its effects on cell proliferation, cell migration, and cell invasion and apoptosis, respectively. The expression of relevant proteins was then examined using western blotting.

Results: Our data showed that Prazosin dose-dependently reduced the viability of MG63 and 143B cells and significantly inhibited their clonogenic ability. Moreover, Prazosin attenuated the cell migration and invasion abilities of MG63 and 143B cells when compared with the NC group. It also accelerated cell apoptosis in mitochondrial pathways by regulating Bcl-2/Bax axis and caspase 3. Furthermore, Prazosin treatment inactivated the Akt/mTOR pathway by down-regulating Akt and mTOR phosphorylation (p-Akt, p-mTOR) and the expression of P70 and cyclin D1.
\end{abstract}

Conclusions: Our data highlights the fact that Prazosin inhibits cell growth, inhibits the motility of osteosarcoma cells, and promotes apoptosis, suggesting that Prazosin is a potential anti-cancer agent in osteosarcoma therapy.

Keywords: Osteosarcoma; Prazosin; Akt/mTOR pathway

Submitted Jan 04, 2019. Accepted for publication Aug 30, 2019.

doi: $10.21037 /$ tcr.2019.09.03

View this article at: http://dx.doi.org/10.21037/tcr.2019.09.03

\section{Introduction}

Osteosarcoma is a primary malignant bone tumor that frequently occurs in adolescents and children, commonly occurring in the femur, tibia and humerus (1-3). Its incidence rate is $3-4 /$ million worldwide, being slightly higher in males than in females $(4,5)$. Due to the high aggressive and rapid metastasis of osteosarcoma, general treatment is severely limited to patients that exhibit metastasis, leading to a poor prognosis of less than $20 \%$
$(6,7)$. However, given the advancement of osteosarcoma treatment technologies in recent years (surgical resection, chemotherapy, and radiotherapy) the survival of patients with osteosarcoma had generally improved, but has more recently stagnated (8). Therefore, it is critical that we find a new anticancer agent that inhibits the metastasis and invasion of osteosarcoma.

Recent research has worked towards this end, searching for new anti-cancer drugs and re-evaluating known drugs that have been used for other diseases, to find their 
potential anti-tumor effects (9). Prazosin [1-(4-amino6,7-dimethoxy-quinazolin-2-yl)-4-(2-furoyl) piperazine], an $\alpha 1$-adrenoceptor antagonist, had generally been used as a sympatholytic drug for the treatment of hypertension and posttraumatic stress disorder (PTSD) (9-11). Recently however, Lin et al. demonstrated that Prazosin also displays an anti-proliferative effect in prostate cancer cells; it accomplished this by inducing apoptosis via resulting in DNA damage stress (12). Similarly, Fuchs et al. confirm that Prazosin treatment inhibits the growth of medullary thyroid carcinoma (MTC) cells, also inducing apoptosis (9). Further studies have also revealed that Prazosin reduces cell proliferation and increases docetaxel-induced toxicity in prostate cancer cells, by modulating autophagy and apoptosis (13).

However, these studies have generally focused on the antiproliferative effects of Prazosin without specifically studying whether Prazosin affects tumor metastasis in osteosarcoma. Therefore, in the present study, we have investigated Prazosin's underlying mechanisms and its effects on the biological behaviors of osteosarcoma cells. In brief, we have observed that Prazosin displays a significant depression of the proliferation, migration, and invasion properties of osteosarcoma cell lines MG63 and 143B, and induced apoptosis, suggesting that it may serve as a novel anti-cancer agent.

\section{Methods}

\section{Cell culture}

Osteosarcoma cell lines MG63 and 143B were obtained from the Cell Bank of the Chinese Academy of Sciences (Shanghai, China). They were cultured in Dulbecco's Modified Eagle Medium (DMEM) medium (HyClone, USA) supplemented with $10 \%$ fetal bovine serum (FBS) (Gibco, USA) at $37{ }^{\circ} \mathrm{C}$ with $5 \% \mathrm{CO}_{2}$.

\section{CCK8 assay}

The MG63 and 143B cells were treated with different concentrations of Prazosin (0, 2.5 , 5, 7.5, 10, 15, 20, 30, 40 , and $50 \mu \mathrm{M}$; MedChemExpress, USA), with Prazosin's effect on cell viability being analyzed by CCK8 assay. After treatment for $24 \mathrm{~h}$, cells were cultured with CCK8 reagent (10 $\mu \mathrm{L} /$ well; Beijing Solarbio Science \& Technology, Beijing, China) at $37^{\circ} \mathrm{C}$ for $90 \mathrm{~min}$ with absorbance being measured at $450 \mathrm{~nm}$.

The effect of Prazosin on MG63 and 143B cells were further analyzed. Approximately $1 \times 10^{3}$ cells were seeded into each well of a 96-well plate and cultured for $24 \mathrm{~h}$. Cells were then treated with either Prazosin or with dimethyl sulfoxide (DMSO) as negative control (NC). Following this treatment for $0,24,48$, and $72 \mathrm{~h}$, cells were cultured with CCK8 reagent at $37{ }^{\circ} \mathrm{C}$ for $90 \mathrm{~min}$ with absorbance being measured at $450 \mathrm{~nm}$.

\section{Clonogenic assay}

About 500 of the cells treated with either Prazosin or DMSO for $24 \mathrm{~h}$ were seeded into mediums to be cultured at $37{ }^{\circ} \mathrm{C}$ with $5 \% \mathrm{CO}_{2}$ for 2 weeks. Afterwards, the colonies were fixed with $1 \mathrm{~mL}$ of $4 \%$ paraformaldehyde for $30 \mathrm{~min}$, followed by staining with crystal violet for $30 \mathrm{~min}$. Photographs were then taken and the number of colonies was counted.

\section{Transwell assay}

Transwell chambers were performed to assess the migration and invasion abilities of MG63 and 143B cells. Before assaying, the Transwell chambers were coated with Matrigel. Following treatment with Prazosin or DMSO for $24 \mathrm{~h}$, the cells in serum-free culture medium were transferred to the upper chamber, with complete medium being added to the lower chamber. After incubation for $24 \mathrm{~h}$, the invaded cells were fixed with $4 \%$ paraformaldehyde, and stained with $0.1 \%$ crystal violet for $20 \mathrm{~min}$. Photograph was then taken and the number of invaded cells was counted under the microscope. The migration assay was similarly conducted except for the absence of Matrigel.

\section{Flow cytometry assay}

In order to assess apoptosis of the cells, the treated MG63 and $143 \mathrm{~B}$ cells were cultured in serum-free medium for $24 \mathrm{~h}$ in order to induce starvation. They were then stained with the Annexin V-FITC-PI apoptosis detection kit (4A Biotech, China) as according to the instructions. The apoptosis rate was analyzed using a flow cytometer (BD FACSCanto II, BD Biosciences, USA), and calculated using BD FACSDiva software.

\section{Western blot assay}

Cells were lysed using ice-cold RIPA Lysis Buffer (CWBIO, China) after $24 \mathrm{~h}$ of Prazosin or DMSO treatment to extract proteins. Twenty $\mu \mathrm{g}$ of protein from each sample 

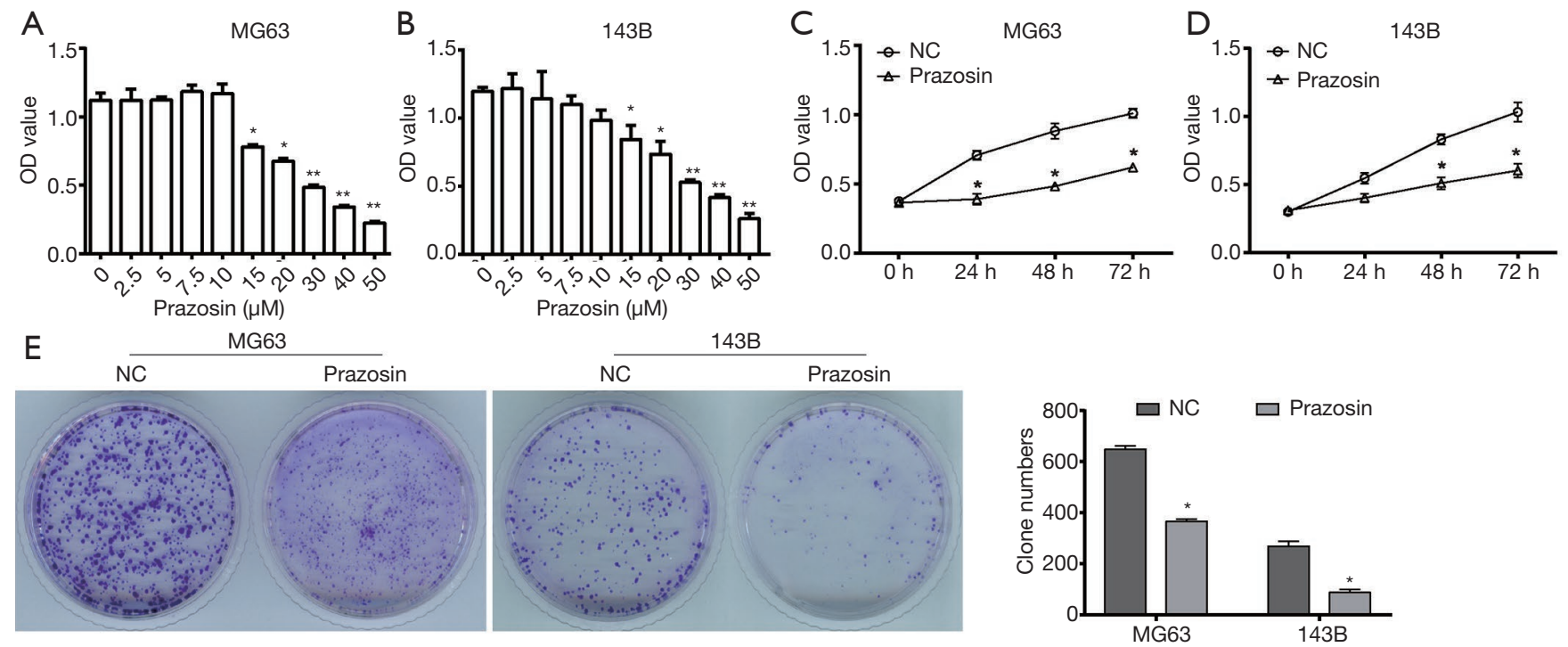

Figure 1 Prazosin inhibits the growth of MG63 and 143B cells. (A,B) Prazosin inhibits the viability of MG63 (A) and 143B (B) cells in a dose-dependent manner after $24 \mathrm{~h}$ treatment; (C) Prazosin $(20 \mu \mathrm{M})$ inhibits the proliferation of MG63 cells after 24, 48 and $72 \mathrm{~h}$ treatment by CCK8 assay; (D) Prazosin $(25 \mu \mathrm{M})$ inhibits the proliferation of $143 \mathrm{~B}$ cells; (E) colony-forming assay showing the inhibitory effects of Prazosin $(20$ or $25 \mu \mathrm{M})$ on clonogenic abilities of MG63 and 143B cells. Prazosin, Prazosin treated group; NC, DMSO treated group. Data is expressed as the mean $\pm \mathrm{SD} .{ }^{*}, \mathrm{P}<0.05$, ${ }^{* *}, \mathrm{P}<0.01$ vs. NC group. SD, standard deviation; DMSO, dimethyl sulfoxide; NC, negative control; OD, optical density.

was electrophoresed on $10 \% 24$ sodium dodecyl sulfatepolyacrylamide gel electrophoresis (SDS-PAGE) gel, and then transferred to a polyvinylidene difluoride (PVDF) membrane (Millipore, Bedford, USA). The membrane was blocked with $5 \%$ non-fat milk for $1 \mathrm{~h}$ prior to incubation with primary antibodies at $4{ }^{\circ} \mathrm{C}$ overnight. Following incubation with secondary antibody for $1 \mathrm{~h}$, the signal was then developed using an enhanced chemiluminescence detection kit. Bcl-2, Bax, active caspase 3, P70, cyclin D1 and glyceraldehyde 3-phosphate dehydrogenase (GAPDH) antibodies were purchased from Proteintech Group (USA), and Akt, p-Akt, mTOR and p-mTOR antibodies were obtained from Cell Signaling Technology (USA). The horseradish peroxidase-conjugated secondary antibodies were obtained from Proteintech Group.

\section{Statistical analysis}

All experiments were repeated in triplicate with the values being presented as mean \pm standard deviation (SD). SPSS 18.0 statistical software was utilized to carry out statistical analysis. Student's $t$-test or one-way analysis of variance (ANOVA) was performed for statistical analysis between groups, and $\mathrm{P}<0.05$ was considered statistically significant.

\section{Results}

\section{Prazosin inhibits the growth of MG63 and 143B cells}

In order to investigate whether Prazosin effects the cell growth of osteosarcoma, MG63 and $143 \mathrm{~B}$ cells were treated with different concentrations of Prazosin $(0,2.5$, $5,7.5,10,15,20,30,40$, and $50 \mu \mathrm{M})$. We found that Prazosin showed no effect on the cell viability of MG63 cells at concentrations lower than $10 \mu \mathrm{M}$ (Figure 1A), whereas it showed significant inhibitory effect at greater concentrations. Similar inhibitory effects were observed in 143 B cells (Figure 1B). The half maximal inhibitory concentration $\left(\mathrm{IC}_{50}\right)$ concentration was $25.29 \mu \mathrm{M}$ in MG63 cells and $35.28 \mu \mathrm{M}$ in $143 \mathrm{~B}$ cells, and $20 \mu \mathrm{M}$ of Prazosin was used in MG63 cells and $25 \mu \mathrm{M}$ was used in $143 \mathrm{~B}$ cells in all the rest experiments as its appropriate effects. In order to substantiate the inhibition of Prazosin in the proliferation of MG63 and 143B cells, CCK8 assay was performed. As shown in Figure 1C, Prazosin significantly blocked the proliferation of MG63 cells when compared with NC cells $(\mathrm{P}<0.05)$, and Prazosin also inhibited the proliferation of $143 \mathrm{~B}$ cells in a time-dependent manner (Figure 1D). Colony-forming assay was performed to further confirm the effect of Prazosin on clonogenic 

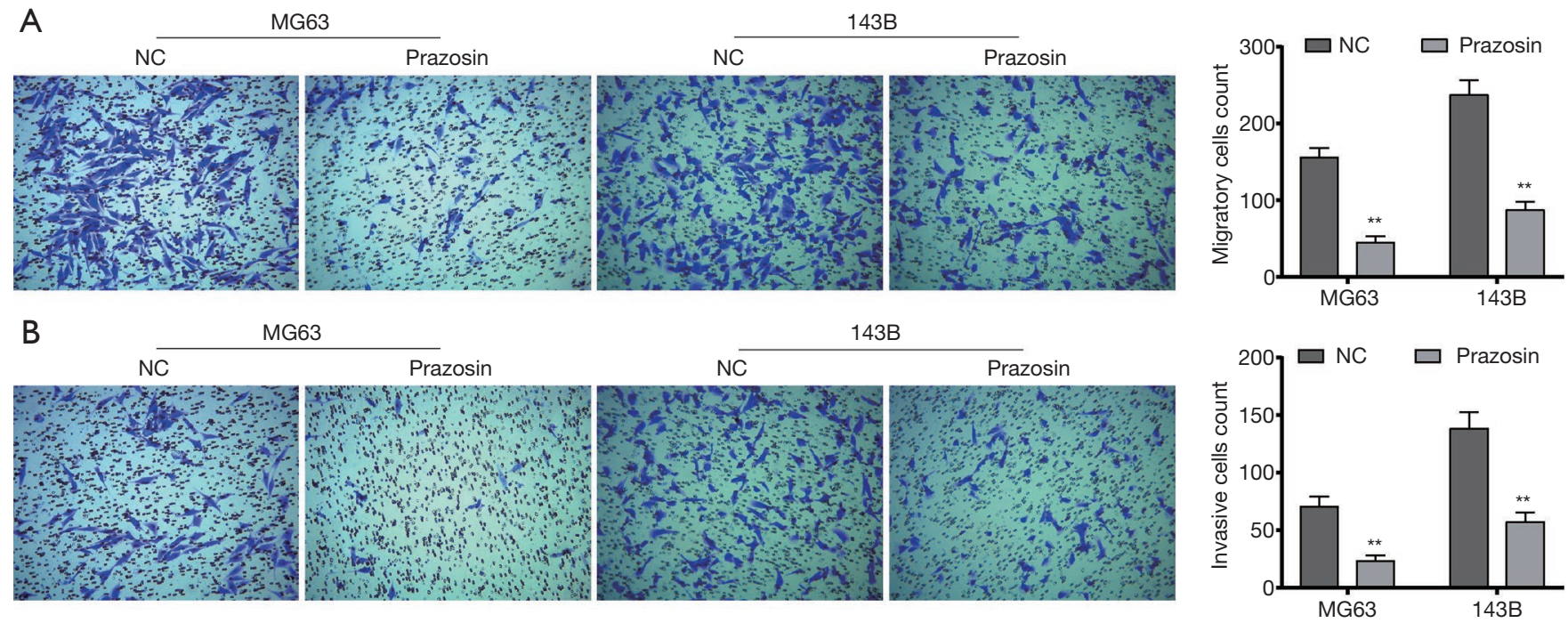

Figure 2 Prazosin inhibits the migration and invasion abilities of MG63 and 143B cells. (A) Prazosin (20 or $25 \mu \mathrm{M})$ inhibits the migration abilities of MG63 and 143B cells after 24 h treatment using Transwell assay; (B) Prazosin (20 or $25 \mu M)$ inhibits the invasion abilities of MG63 and 143B cells after 24 h treatment. Amplification, 100. Prazosin, Prazosin treated group. Data is expressed as the mean \pm SD. **, $\mathrm{P}<0.01$ vs. NC group. SD, standard deviation; NC, negative control.

abilities of MG63 and 143B cells. Our data revealed a significant decrease in the number and size of colonies in Prazosin treated cells compared with NC group $(\mathrm{P}<0.05$, Figure 1E). Collectively, these data suggest that Prazosin inhibits the viability and proliferation of osteosarcoma cells in vitro.

\section{Prazosin decreases the migration and invasion abilities of MG63 and 143B cells}

It is well known that the invasion and metastasis properties of cancer cells are the main causes for poor prognosis in osteosarcoma. Therefore, we examined Prazosin's effect on these properties in MG63 and 143B cells using a Transwell assay in vitro. As shown in Figure $2 A$, Prazosin led to a significant decrease in the migration abilities of MG63 and $143 \mathrm{~B}$ cells compared with $\mathrm{NC}$ group $(\mathrm{P}<0.01)$. Meanwhile, the number of invasive cells was also significantly decreased by Prazosin treatment $(\mathrm{P}<0.01$, Figure $2 B)$. Overall, Prazosin displays a significant anti-cancer role in the migration and invasion abilities of osteosarcoma cells.

\section{Prazosin induces apoptosis in MG63 and 143B cells}

Given that Prazosin was found to inhibit cell growth, cell apoptosis was assessed using flow cytometry to determine the effect of Prazosin on cell survival of osteosarcoma. Flow cytometric analysis showed that Prazosin significantly increased the rate of apoptosis induced by starvation in MG63 cells compared with $\mathrm{NC}$ group $(\mathrm{P}<0.05$, Figure $3 A)$. Additionally, the rate of apoptosis in $143 \mathrm{~B}$ cells was also promoted by Prazosin (Figure 3A). To investigate which apoptotic pathway was induced by Prazosin, western blotting was used to detect the expression level of Bcl-2, Bax and active caspase 3. As expected, the expression level of anti-apoptotic protein Bcl-2 was down-regulated by Prazosin compared with NC group $(\mathrm{P}<0.01)$, while expression level of pro-apoptotic proteins $\mathrm{Bax}$ and active caspase 3 was simultaneously up-regulated $(\mathrm{P}<0.01$, Figure $3 B)$. The above suggests that Prazosin induces the mitochondrial apoptotic pathway in MG63 and 143B cells.

\section{Prazosin inhibits activity of the Akt/mTOR pathway in MG63 and 143B cells}

As everyone knows, the Akt/mTOR pathway plays a pivotal role in regulating cell growth and survival, being particularly involved in progression of osteosarcoma. In the present study, we examined the expression levels of crucial proteins in the Akt/mTOR pathway to confirm whether the pathway is involved in the anticancer effects 

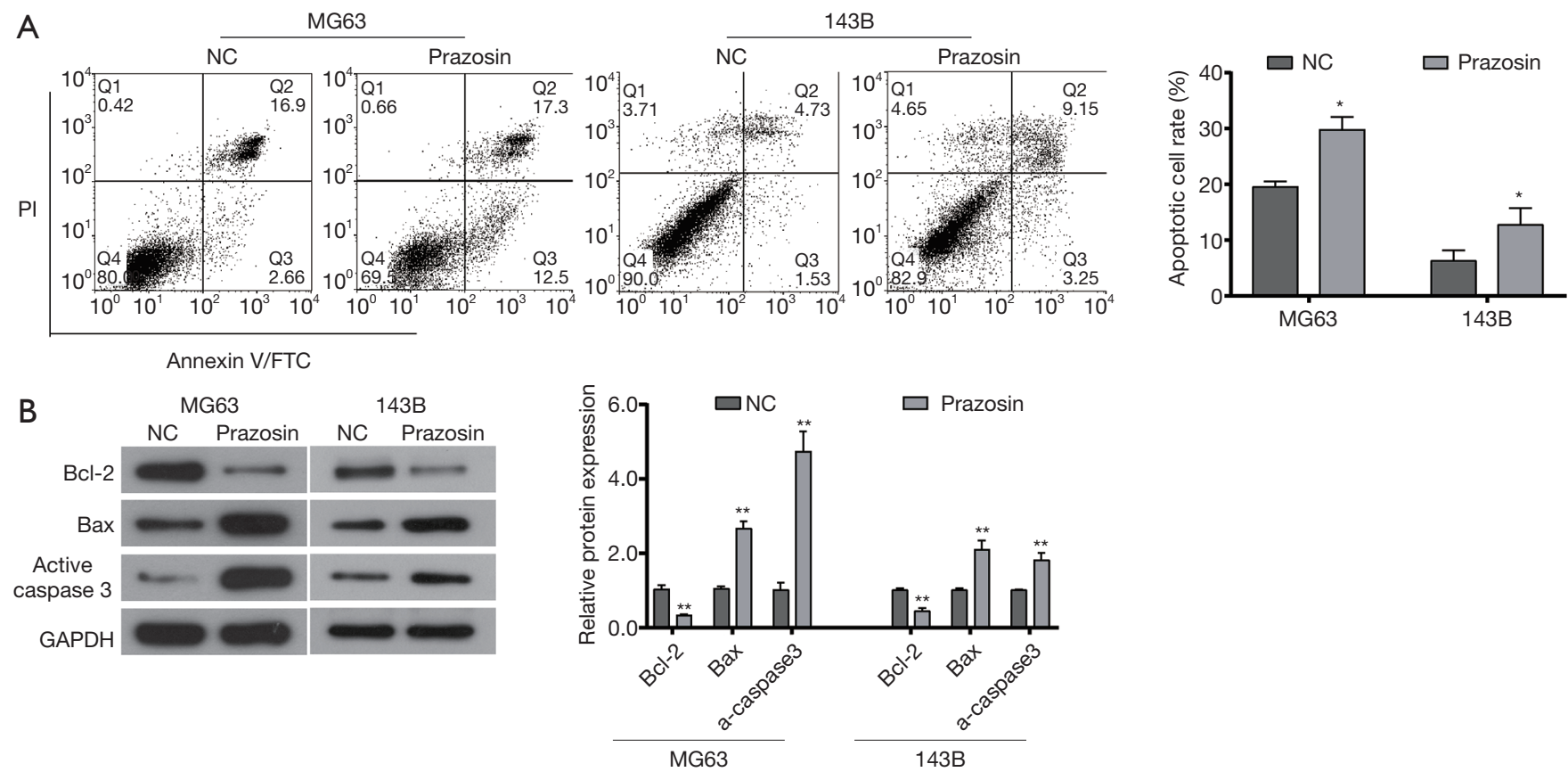

Figure 3 Prazosin induces apoptosis in MG63 and 143B cells. (A) After MG63 and 143B cells were treated with Prazosin (20 or $25 \mu$ M), the rate of apoptosis significantly increased; (B) after MG63 and 143B cells were treated with Prazosin (20 or $25 \mu \mathrm{M})$, Western blotting was used to examine expression of apoptosis-related proteins. Prazosin, Prazosin treated group. Data is expressed as the mean $\pm \mathrm{SD}$. *, $\mathrm{P}<0.05$, **, $\mathrm{P}<0.01$ vs. NC group. SD, standard deviation; NC, negative control.
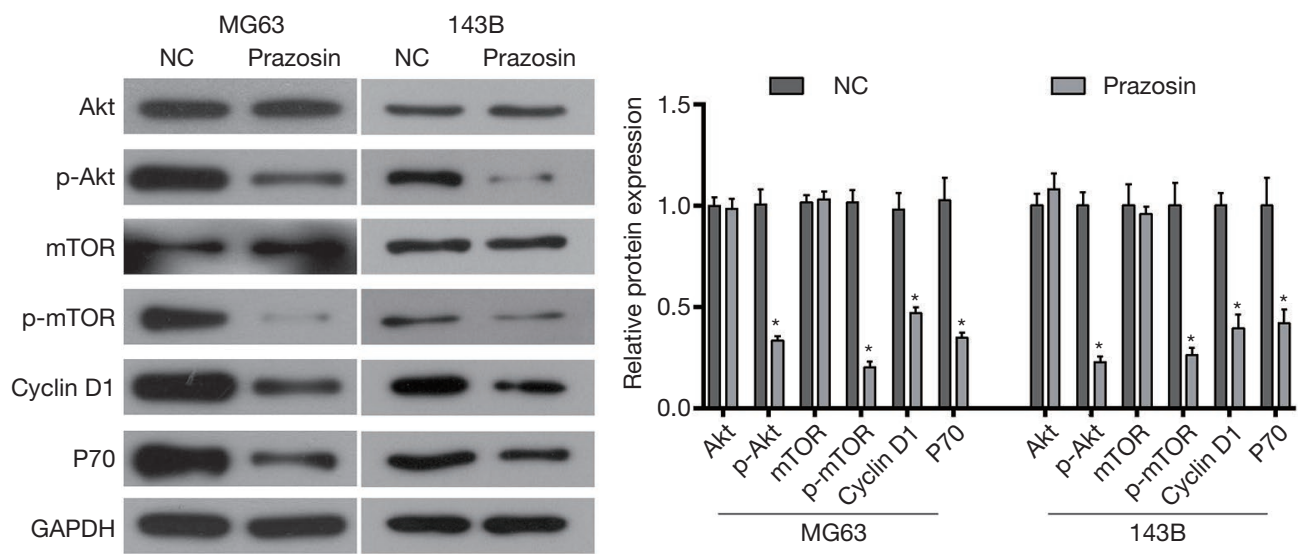

Figure 4 Prazosin suppresses the PI3K/Akt pathway in MG63 and 143B cells. After MG63 and 143B cells were treated with Prazosin (20 or $25 \mu \mathrm{M}$ ), the expression level of phosphorylation levels of Akt (p-Akt) and mTOR (p-mTOR) and cyclin D1, P70 were significantly decreased. Prazosin, Prazosin treated group. Data is expressed as the mean \pm SD. *, $\mathrm{P}<0.05$ vs. NC group. SD, standard deviation; NC, negative control.

of Prazosin. Our data showed that the phosphorylation levels of Akt (p-Akt) and mTOR (p-mTOR) were significantly attenuated by Prazosin in both MG63 and 143 B cells. Furthermore, it showed that the expression levels of downstream proteins p70S6k (P70) and cyclin D1 were also decreased $(\mathrm{P}<0.05$, Figure 4$)$. This data suggests that the Akt/mTOR pathway might be involved in the anti-tumor effects of Prazosin. 


\section{Discussion}

Metastasis is an important factor affecting the prognosis of patients with osteosarcoma, especially the occurrence of lung metastasis (14). Therefore, blocking tumor metastasis and invasion is a necessary strategy for osteosarcoma therapy. It has been well-documented that Prazosin enhances the apoptosis rate in a number of tumor cells, displaying anti-growth activity in prostate cancer $(12,13,15)$, glioblastoma (16), and MTC cells (9). In the present study, we have tested and identified Prazosin as a novel anti-cancer agent in osteosarcoma cells. We have shown that Prazosin possesses a significant inhibitory effect on cell viability of osteosarcoma MG63 and 143B cells in a dose- and timedependent manner in vitro. Furthermore, we've shown that Prazosin inhibits both cell migration and invasion, and also induces apoptosis, further displaying an anti-tumor role in the progression and motility of osteosarcoma cells.

Dysregulated apoptosis is one of the common hallmarks of tumor cells, reducing apoptosis is a general mechanism of survival of osteosarcoma cells. In this study, our data confirmed a significant induction in apoptosis in Prazosin treated cells compared with the NC group. It has been shown that apoptosis involves numerous proteolytic events mainly mediated by the family of cysteine proteases, including the activated caspase 3 , a pivotal executioner to trigger apoptosis (17). It has already shown that Prazosin induces apoptosis in prostate cancer PC-3 cells by triggering mitochondria mediated caspase cascades through targeting DNA (12). Our data confirm that Prazosin induces apoptosis by up-regulating the level of active caspase 3 in MG63 and $143 \mathrm{~B}$ cells, suggesting that activating the caspase cascades is involved in the promotion of apoptosis induced by Prazosin. The Bcl-2 family also plays an essential role in initiation of apoptosis by triggering the mitochondrial pathway $(18,19)$. In general, a decreasing ratio of $\mathrm{Bcl}-2$, a pivotal anti-apoptotic protein located in the mitochondria, to Bax, a crucial proapoptotic protein mainly located in the cytoplasm, promotes apoptosis $(20,21)$. In our study, a significant decrease in the expression level of Bcl-2 and concurrent increase in Bax were observed in MG63 and 143B cells exposed to Prazosin, indicating that apoptosis promoted by Prazosin is specifically triggered in the mitochondrial pathway. Autophagy, also known as type II programmed cell death, is another way of causing cell death. Prazosin also has been reported to be able to induce autophagy in prostate cancer $(13,15)$ and H9C2 cells (22). As described above, Prazosin might be used as an effective anti-tumor agent for cancer therapy, and whether
Prazosin induces autophagy in osteosarcoma cells will be the focus of our further study.

Abnormalities in the PI3K/Akt/mTOR pathway are frequently observed in various cancers and are correlated with tumor cell growth and survival. Aberration of PI3K/ Akt pathway is frequently observed in cancers including osteosarcoma (23). More specifically, growing evidence reveals that some anti-tumor agents, such as Ferulic acid (8), Lupeol (24) and Andrographolide (25), blocks the PI3K/Akt/ mTOR pathway, exerting significant inhibitory effects on cell growth and survival of osteosarcoma and even enhancing the anti-cancer effects of cisplatin (26). Furthermore, Yang et al. report that the Akt/mTOR pathway is involved in Prazosin-induced autophagy in rat embryonic ventricular myoblast H9C2 cells (22). The Akt pathway is also observed to be inhibited by Prazosin in glioblastoma-initiating cells (16). Consistent with these previous studies, we have found that the phosphorylation levels of Akt and mTOR were down-regulated by Prazosin. Similarly, we found that expression levels of P70 and cyclin D1 were also decreased. P70, a downstream target protein of mTOR, modulates protein synthesis and is involved in cell proliferation and cell cycle. It has been demonstrated that P70 is overactivated in osteosarcoma tissues, being associated with the progression of osteosarcoma (27). Cyclin D1, a key regulator in the cell cycle, promotes cell proliferation. Cyclin D1 overexpression is frequently observed in tumors and associated with tumorigenesis (28). Given the above, the Akt/ mTOR pathway may be involved in the anti-tumor effects of Prazosin on the proliferation, invasion, and survival of osteosarcoma cells.

\section{Conclusions}

In the current study, we highlight that Prazosin inhibits the cell growth and motility of MG63 and 143B cells. We have also shown that it promotes apoptosis in the mitochondrial pathway. In sum, as Prazosin inhibits cell survival and metastasis, our data suggests that it may serve as a potential anti-cancer agent in osteosarcoma therapy.

\section{Acknowledgments}

Funding: None.

\section{Footnote}

Conflicts of Interest: All authors have completed the ICMJE 
uniform disclosure form (available at http://dx.doi. org/10.21037/tcr.2019.09.03). The authors have no conflicts of interest to declare.

Ethical Statement: The authors are accountable for all aspects of the work in ensuring that questions related to the accuracy or integrity of any part of the work are appropriately investigated and resolved. This study was conducted in accordance with the Declaration of Helsinki (as revised in 2013). The study was approved by the ethics committee of The First Central Hospital of Baoding (No. 2019061). Individual informed consent was waived.

Open Access Statement: This is an Open Access article distributed in accordance with the Creative Commons Attribution-NonCommercial-NoDerivs 4.0 International License (CC BY-NC-ND 4.0), which permits the noncommercial replication and distribution of the article with the strict proviso that no changes or edits are made and the original work is properly cited (including links to both the formal publication through the relevant DOI and the license). See: https://creativecommons.org/licenses/by-nc-nd/4.0/.

\section{References}

1. Geller DS, Gorlick R. Osteosarcoma: a review of diagnosis, management, and treatment strategies. Clin Adv Hematol Oncol 2010;8:705-18.

2. Kansara M, Teng MW, Smyth MJ, et al. Translational biology of osteosarcoma. Nat Rev Cancer 2014;14:722-35.

3. Zhang H, Guo X, Feng X, et al. MiRNA-543 promotes osteosarcoma cell proliferation and glycolysis by partially suppressing PRMT9 and stabilizing HIF-1 $\alpha$ protein. Oncotarget 2017;8:2342-55.

4. Mirabello L, Troisi RJ, Savage SA. Osteosarcoma incidence and survival rates from 1973 to 2004: data from the surveillance, epidemiology, and end results program. Cancer 2009;115:1531-43.

5. Anderson ME. Update on survival in osteosarcoma. Orthop Clin North Am 2016;47:283-92.

6. Allison DC, Carney SC, Ahlmann ER, et al. A metaanalysis of osteosarcoma outcomes in the modern medical era. Sarcoma 2012;2012:704872.

7. Jin $\mathrm{H}$, Jin $\mathrm{X}$, Zhang $\mathrm{H}$, et al. Circular RNA hsacirc-0016347 promotes proliferation, invasion and metastasis of osteosarcoma cells. Oncotarget 2017;8:25571-81.

8. Wang T, Gong $\mathrm{X}$, Jiang R, et al. Ferulic acid inhibits proliferation and promotes apoptosis via blockage of PI3K/Akt pathway in osteosarcoma cell. Am J Transl Res 2016;8:968-80.

9. Fuchs R, Schwach G, Stracke A, et al. The antihypertensive drug Prazosin induces apoptosis in the medullary thyroid carcinoma cell line TT. Anticancer Res 2015;35:31-8.

10. Nakamura T, Kamishikiryo J, Morita T. Prazosinstimulated release of hepatic triacylglyceride lipase from primary cultured rat hepatocytes is involved in the regulation of cAMP-dependent protein kinase through activation of the $\mathrm{Ca}(2+) /$ calmodulin-dependent protein kinase-II. Pharmacol Rep 2016;68:649-53.

11. Petrakis IL, Desai N, Gueorguieva R, et al. Prazosin for veterans with posttraumatic stress disorder and comorbid alcohol dependence: a clinical trial. Alcohol Clin Exp Res 2016;40:178-86.

12. Lin SC, Chueh SC, Hsiao CJ, et al. Prazosin displays anticancer activity against human prostate cancers: targeting DNA and cell cycle. Neoplasia 2007;9:830-9.

13. Spencer BH, McDermott CM, Chess-Williams R, et al. Prazosin but not tamsulosin sensitises PC-3 and $\mathrm{LNCaP}$ prostate cancer cells to docetaxel. Pharmacology 2018;102:10-8.

14. Faisham WI, Mat Saad AZ, Alsaigh LN, et al. Prognostic factors and survival rate of osteosarcoma: a singleinstitution study. Asia Pac J Clin Oncol 2017;13:e104-10.

15. Forbes A, Anoopkumar-Dukie S, Chess-Williams R, et al. Relative cytotoxic potencies and cell death mechanisms of $\alpha 1$-adrenoceptor antagonists in prostate cancer cell lines. Prostate 2016;76:757-66.

16. Assad Kahn S, Costa SL, Gholamin S, et al. The antihypertensive drug Prazosin inhibits glioblastoma growth via the $\mathrm{PKC} \delta$-dependent inhibition of the AKT pathway. EMBO Mol Med 2016;8:511-26.

17. Gui D, Guo Y, Wang F, et al. Astragaloside IV, a novel antioxidant, prevents glucose-induced podocyte apoptosis in vitro and in vivo. PLoS One 2012;7:e39824.

18. Martinou JC, Youle RJ. Mitochondria in apoptosis: Bcl2 family members and mitochondrial dynamics. Dev Cell 2011;21:92-101.

19. Wu R, Tang S, Wang M, et al. MicroRNA-497 induces apoptosis and suppresses proliferation via the Bcl-2/ Bax-caspase9-caspase3 pathway and cyclin D2 protein in HUVECs. PLoS One 2016;11:e0167052.

20. Soares NCP, Teodoro AJ, Oliveira FL, et al. Lycopene induce apoptosis in human prostate cells and alters the expression of Bax and Bcl-2 genes. LWT-Food Science 
and Technology 2014;59:1290-7.

21. Liu G, Wang T, Wang T, et al. Effects of apoptosis-related proteins caspase-3, Bax and Bcl-2 on cerebral ischemia rats. Biomed Rep 2013;1:861-7.

22. Yang YF, Wu CC, Chen WP, et al. Prazosin induces p53mediated autophagic cell death in H9C2 cells. Naunyn Schmiedebergs Arch Pharmacol 2011;384:209-16.

23. Chen J, Yao D, Yuan H, et al. Dipsacus asperoides polysaccharide induces apoptosis in osteosarcoma cells by modulating the PI3K/Akt pathway. Carbohydr Polym 2013;95:780-4.

24. Liu Y, Bi T, Dai W, et al. Lupeol induces apoptosis and cell cycle arrest of human osteosarcoma cells through PI3K/AKT/mTOR pathway. Technol Cancer Res Treat 2016;15:NP16-24.

Cite this article as: An M, Ma WH, Jia HW, Li YW, Feng JJ, Meng J, Qi H, Liu J. Prazosin inhibits the growth and mobility of osteosarcoma cells. Transl Cancer Res 2019;8(5):1997-2004. doi: $10.21037 /$ tcr.2019.09.03
25. Liu Y, Zhang Y, Zou J, et al. Andrographolide induces autophagic cell death and inhibits invasion and metastasis of human osteosarcoma cells in an autophagy-dependent manner. Cell Physiol Biochem 2017;44:1396-410.

26. Liu B, Yan S, Qu L, et al. Celecoxib enhances anticancer effect of cisplatin and induces anoikis in osteosarcoma via PI3K/Akt pathway. Cancer Cell Int 2017;17:1.

27. Zhou Q, Deng Z, Zhu Y, et al. mTOR/p70S6K signal transduction pathway contributes to osteosarcoma progression and patients' prognosis. Med Oncol 2010;27:1239-45.

28. Qie S, Diehl JA. Cyclin D1, cancer progression, and opportunities in cancer treatment. J Mol Med (Berl) 2016;94:1313-26. 